\title{
Interactive Association Between CYP2C9 rs2860905 Polymorphism and Atrial Fibrillation on Ischemic Stroke in Taiwan Biobank Participants
}

\author{
Jui-Wen Peng' \\ Oswald Ndi Nfor ${ }^{2}$ \\ Chien-Chang $\mathrm{Ho}^{3,4}$ \\ Shu-Yi Hsu ${ }^{2}$ \\ Chia-Chi Lung ${ }^{2}$ \\ Disline Manli Tantoh ${ }^{2,5}$ \\ Ming-Chih Chou' \\ Yung-Po Liaw $\mathbb{D}^{2,5}$ \\ 'Institute of Medicine, Chung Shan \\ Medical University, Taichung, 4020I, \\ Taiwan; ${ }^{2}$ Department of Public Health \\ and Institute of Public Health, Chung \\ Shan Medical University, Taichung, 4020I, \\ Taiwan; ${ }^{3}$ Department of Physical \\ Education, Fu-Jen Catholic University, \\ New Taipei City, 24205, Taiwan; \\ ${ }^{4}$ Research and Development Center for \\ Physical Education, Health, and \\ Information Technology, Fu Jen Catholic \\ University, New Taipei, 24205, Taiwan; \\ ${ }^{5}$ Department of Medical Imaging, Chung \\ Shan Medical University Hospital, \\ Taichung City, 4020I, Taiwan
}

Purpose: Ischemic stroke accounts for approximately $85 \%$ of all strokes. Risk factors include atrial fibrillation, metabolic disorders, and genetic and lifestyle factors. There is limited evidence to support the association between atrial fibrillation and the risk of ischemic stroke based on genetic variants. We assessed the relationship between ischemic stroke and atrial fibrillation among participants in Taiwan Biobank (TWB) based on the rs2860905 variant of the cytochrome P450 Family 2 Subfamily C Member 9 (CYP2C9) gene.

Materials and Methods: Using logistic regression analysis, we estimated the odds ratios (OR) and 95\% confidence intervals (CI) for ischemic stroke among 17,726 biobank adults recruited from 2008 through 2015.

Results: Of the eligible participants $(n=17,726), 906$ were identified with ischemic stroke. Atrial fibrillation was positively associated with ischemic stroke (OR=3.70; 95\% CI, 2.21 6.20), whereas the rs 2860905 variant was not. The OR for ischemic stroke among those with GA/AA genotype was 1.00 (95\% CI, 0.82-1.22) compared to those with the GG genotype. Based on the genotype-stratified analysis, the OR for ischemic stroke was 4.68 (95\% CI, 2.70-8.09) among individuals with GG genotype who had atrial fibrillation compared to those who did not.

Conclusion: These results demonstrate that the GG genotype of the CYP2C9 rs2860905 variant appears to enhance the risk of ischemic stroke among adults in Taiwan. It could be essential to factor this genotype-specific contributor to ischemic stroke into clinical and experimental investigations of the disease in Taiwan.

Keywords: genetic variation, risk prediction, stroke

\section{Introduction}

Stroke remains one of the significant health threats in Taiwan. Globally, about 13.7 million people over the age of 25 develop stroke each year, ${ }^{1}$ and the incidence appears to be higher in men than women ( 52 vs 48 ). There are three main types, but generally, ischemic stroke is the most frequent type, especially in people under $70{ }^{1}$ Ischemic stroke accounts for almost $85 \%$ of all stroke. ${ }^{2}$ According to a previous report in Taiwan, ischemic stroke is predominant among adults aged 65 and $69 .{ }^{3}$

Several metabolic and lifestyle factors play a role in the development of ischemic stroke. ${ }^{4}$ Atrial fibrillation (dysrhythmia) is among the independent factors previously associated with ischemic stroke in Taiwanese ${ }^{5}$ and other populations. ${ }^{6,7}$ Dysrhythmia affects millions of people worldwide and has been linked to an interplay between genetic predisposition and several other factors. ${ }^{8}$ 
Stroke that develops due to AF is associated with a higher fatality because of large thrombi in the atria. ${ }^{9}$ Warfarin, a plasma-bound anticoagulant, is commonly used to decrease stroke risk. ${ }^{9}$ According to a previous meta-analysis, warfarin use was associated with a $64 \%$ decrease in stroke risk. ${ }^{10}$ Despite these benefits, it has been suggested that sensitivity to this anticoagulant is affected by genetic variation. ${ }^{9}$ The Cytochrome P450 2C9 (CYP2C9) gene is among the genes whose variants have previously shown associations with warfarin dose. ${ }^{11}$ It is responsible for the metabolic clearance of warfarin. Rs2860905 is among the CYP2C9 variants that remained significantly associated with warfarin dose after experiment-wise adjustments for multiple testing. ${ }^{12}$ Compared to other CYP2C9 variants combined, rs2860905 has been associated with a better prediction of warfarin dose among Caribbean Hispanics of Puerto Rico. ${ }^{13}$ Assessing the pharmacogenomic influence on warfarin across different ethnicity is essential in clinical pharmacology. This study evaluated the relationship between ischemic stroke and atrial fibrillation among Taiwan Biobank participants based on the rs2860905 variant of the CYP2C9 gene.

\section{Methods}

\section{Data Source}

Genetic data from 2008 through 2015 were obtained from the TWB database. Through the Health and Welfare Data Science Center (HWDC), genetic data were linked to population data (from 1998 through 2015) available in the NHIRD. Linkage of both databases was made using personal identification numbers. The linked data provided information about ischemic stroke, atrial fibrillation, and warfarin use. Written informed consents had been obtained from all participants before assessments in TWB centers. The data accessed comply with relevant data protection and privacy regulations.

The Institutional Review Board of Chung Shan Medical University approved this study.

\section{Study Participants}

We obtained data of 17,985 TWB participants and excluded those with unfinished questionnaires $(n=37)$ and incomplete genotype information $(\mathrm{n}=109)$. We also excluded 113 participants with hemorrhagic stroke. Finally, 906 participants with ischemic stroke and 16,820 controls were included in our analysis.

\section{Definition of the Variables}

We identified ischemic stroke and atrial fibrillation using the International Classification of Diseases Clinical Modification, 9th Revision (ICD-9-CM) diagnosis codes 433-437 and 427.3, respectively. This was based on either two outpatient consultations or inpatient admission. The lifestyle variables used in the current study have been previously defined. ${ }^{14}$

\section{Selection of Variant and Genotyping}

We chose the rs2860905 variant from previous studies using search engines such as GWAS Catalog, Google Scholar, PubMed, and others. We chose this variant because of its association with warfarin. ${ }^{12,15,16}$ Our samples were genotyped for this variant SNP by Affymetrix using the Axiom ${ }^{\mathrm{TM}}$ Genome-Wide Array Plate System (Affymetrix, Santa Clara, CA, USA). The rs2860905 variant passed quality control: the call rate was greater than 95\% and the p-value for the Hardy-Weinberg equilibrium (HWE) test was greater than $1.0 \times 10^{-3}$. The minor allele frequency (MAF) was $>0.05$.

\section{Statistical Analysis}

We performed statistical analyses using the statistical analysis system (SAS) software (version 9.4) and PLINK (version 1.09 beta). We performed the $t$-test and Chisquare test for the continuous and categorical variables. We investigated the association between atrial fibrillation and rs2860905) in relation to ischemic stroke using logistic multiple regression analysis. Variables included in the model were age, sex, alcohol drinking, educational level, smoking, physical activity, body mass index, diabetes, hypertension, hyperlipidemia, and warfarin use. We estimated the corresponding odds ratios (ORs) with their $95 \%$ confidence intervals.

\section{Results}

Baseline characteristics are provided in Table 1. Of the 17,726 eligible individuals, we identified 906 with ischemic stroke. Among them, 773 were those with the GG genotype, and 133 carried the GA/AA genotype. About $1.21 \%$ of patients with ischemic stroke and $0.65 \%$ of control individuals had a history of warfarin use. In our overall analysis (Table 2), atrial fibrillation was associated with an increased risk of ischemic stroke (OR $=3.70 ; 95 \%$ CI, 2.21-6.20). We found no significant association between the rs2860905 variant and ischemic stroke risk. 
Table I Baseline Characteristics of Participants

\begin{tabular}{|c|c|c|c|c|c|}
\hline & \multicolumn{2}{|c|}{ Control } & \multicolumn{2}{|c|}{$\begin{array}{l}\text { Ischemic } \\
\text { Stroke }\end{array}$} & \multirow[t]{2}{*}{$p$-value } \\
\hline & $\mathbf{N}$ & $\%$ & $\mathbf{N}$ & $\%$ & \\
\hline rs2860905 & & & & & 0.7450 \\
\hline GG & 14,284 & 84.92 & 773 & 85.32 & \\
\hline GA/AA & 2536 & 15.08 & 133 & 14.68 & \\
\hline Atrial fibrillation & & & & & $<0.0001$ \\
\hline No & 16,748 & 99.57 & 879 & 97.02 & \\
\hline Yes & 72 & 0.43 & 27 & 2.98 & \\
\hline Sex & & & & & 0.0490 \\
\hline Women & 8715 & 51.81 & 439 & 48.45 & \\
\hline Men & 8105 & 48.19 & 467 & 51.55 & \\
\hline Age, y (Mean $\pm S D)$ & 48.33 & 10.90 & 58.48 & 8.14 & $<0.0001$ \\
\hline Educational level & & & & & $<0.0001$ \\
\hline Elementary school & 902 & 5.36 & 120 & 13.25 & \\
\hline $\begin{array}{l}\text { Junior/Senior high } \\
\text { school }\end{array}$ & 6492 & 38.6 & 421 & 46.47 & \\
\hline University \& above & 9426 & 56.04 & 365 & 40.29 & \\
\hline Smoking & & & & & 0.4390 \\
\hline No & 12,704 & 75.53 & 674 & 74.39 & \\
\hline Yes & 4116 & 24.47 & 232 & 25.61 & \\
\hline Alcohol intake & & & & & 0.0070 \\
\hline No & 15,098 & 89.76 & 788 & 86.98 & \\
\hline Yes & 1722 & 10.24 & 118 & 13.02 & \\
\hline Physical activity & & & & & $<0.0001$ \\
\hline No & 10,027 & 59.61 & 381 & 42.05 & \\
\hline Yes & 6793 & 40.39 & 525 & 57.95 & \\
\hline BMI, $\mathrm{kg} / \mathrm{m}^{2}$ & & & & & $<0.0001$ \\
\hline$<18.5$ & 508 & 3.02 & 18 & 1.99 & \\
\hline$|8.5 \leq \mathrm{BM}|<24$ & 8155 & 48.48 & 372 & 41.06 & \\
\hline $24 \leq \mathrm{BMI}<27$ & 4814 & 28.62 & 302 & 33.33 & \\
\hline $\mathrm{BMI} \geq 27$ & 3343 & 19.88 & 214 & 23.62 & \\
\hline Diabetes mellitus & & & & & $<0.0001$ \\
\hline No & 14,746 & 87.67 & 577 & 63.69 & \\
\hline Yes & 2074 & 12.33 & 329 & 36.31 & \\
\hline Hypertension & & & & & $<0.0001$ \\
\hline No & 13,230 & 78.66 & 355 & 39.18 & \\
\hline Yes & 3590 & 21.34 & 551 & 60.82 & \\
\hline Hyperlipidemia & & & & & $<0.0001$ \\
\hline No & 12,059 & 71.69 & 328 & 36.2 & \\
\hline Yes & 4761 & 28.31 & 578 & 63.8 & \\
\hline Warfarin use & & & & & 0.0460 \\
\hline No & 16,710 & 99.35 & 895 & 98.79 & \\
\hline Yes & 110 & 0.65 & 11 & 1.21 & \\
\hline
\end{tabular}

Abbreviations: BMI, body mass index; SD, standard deviation.
Table 2 The Odds of Ischemic Stroke Among General Participants

\begin{tabular}{|c|c|c|c|}
\hline & OR & $95 \% \mathrm{Cl}$ & $p$-value \\
\hline \multicolumn{4}{|l|}{ rs2860905 (ref: GG) } \\
\hline GA/AA & 1.00 & $0.82-1.22$ & 0.9950 \\
\hline \multicolumn{4}{|l|}{ Atrial fibrillation (ref: No) } \\
\hline Yes & 3.70 & $2.21-6.20$ & $<0.0001$ \\
\hline \multicolumn{4}{|l|}{ Sex (ref: Women) } \\
\hline Men & 1.04 & $0.87-1.23$ & 0.6750 \\
\hline Age & 1.07 & $1.06-1.08$ & $<0.0001$ \\
\hline \multicolumn{4}{|l|}{ Smoking (ref: No) } \\
\hline Yes & 0.90 & $0.74-1.09$ & 0.2880 \\
\hline \multicolumn{4}{|l|}{ Alcohol intake (ref: No) } \\
\hline Yes & 1.21 & $0.96-|.5|$ & 0.1080 \\
\hline \multicolumn{4}{|l|}{ BMI (ref: $\mid 8.5 \leq$ BMI<24) } \\
\hline$<18.5$ & 1.30 & $0.79-2.14$ & 0.3050 \\
\hline $24 \leq \mathrm{BMI}<27$ & 0.97 & $0.82-1.15$ & 0.7590 \\
\hline $\mathrm{BMI} \geq 27$ & 1.01 & $0.84-1.23$ & 0.9020 \\
\hline \multicolumn{4}{|l|}{ Diabetes mellitus (ref: No) } \\
\hline Yes & 1.49 & $1.26-1.75$ & $<0.0001$ \\
\hline \multicolumn{4}{|l|}{ Hypertension (ref: No) } \\
\hline Yes & 2.28 & $1.94-2.69$ & $<0.0001$ \\
\hline \multicolumn{4}{|l|}{ Hyperlipidemia (ref: No) } \\
\hline Yes & 1.66 & $1.4 \mathrm{I}-1.96$ & $<0.0001$ \\
\hline \multicolumn{4}{|l|}{ Warfarin use (ref: No) } \\
\hline Yes & 0.54 & $0.26-1.11$ & 0.0910 \\
\hline
\end{tabular}

Note: Adjusted for physical activity and educational level.

The OR for ischemic stroke among those with GA/AA genotype was $1.00(95 \% \mathrm{CI}, 0.82-1.22)$ compared to GG homozygotes. We also found positive associations between ischemic stroke risk and diabetes $(\mathrm{OR}=1.49 ; 95 \% \mathrm{CI}$, 1.26-1.75), hypertension ( $\mathrm{OR}=2.28$; 95\% CI, 1.94-2.69), and hyperlipidemia $(\mathrm{OR}=1.66 ; 95 \% \mathrm{CI}, 1.41-1.96)$. We observed that the ischemic stroke risk associated with warfarin use was lower but not significant $(\mathrm{OR}=0.54$; 95\% CI, 0.26-1.11). In the genotype-stratified analysis (Table 3), atrial fibrillation remained a significant risk factor only among those with $\mathrm{GG}$ genotype $(\mathrm{OR}=4.68$; 95\% CI, 2.70-8.09). Compared with the GG genotype (Table 4), a lower odds ratio was observed among GA/ AA individuals with atrial fibrillation $(\mathrm{OR}=0.08)$ and higher estimates among the same individuals with no atrial fibrillation $(\mathrm{OR}=1.04)$ even though they were not 
Table 3 The Risk of Ischemic Stroke Based on rs2860905 Variant Genotypes

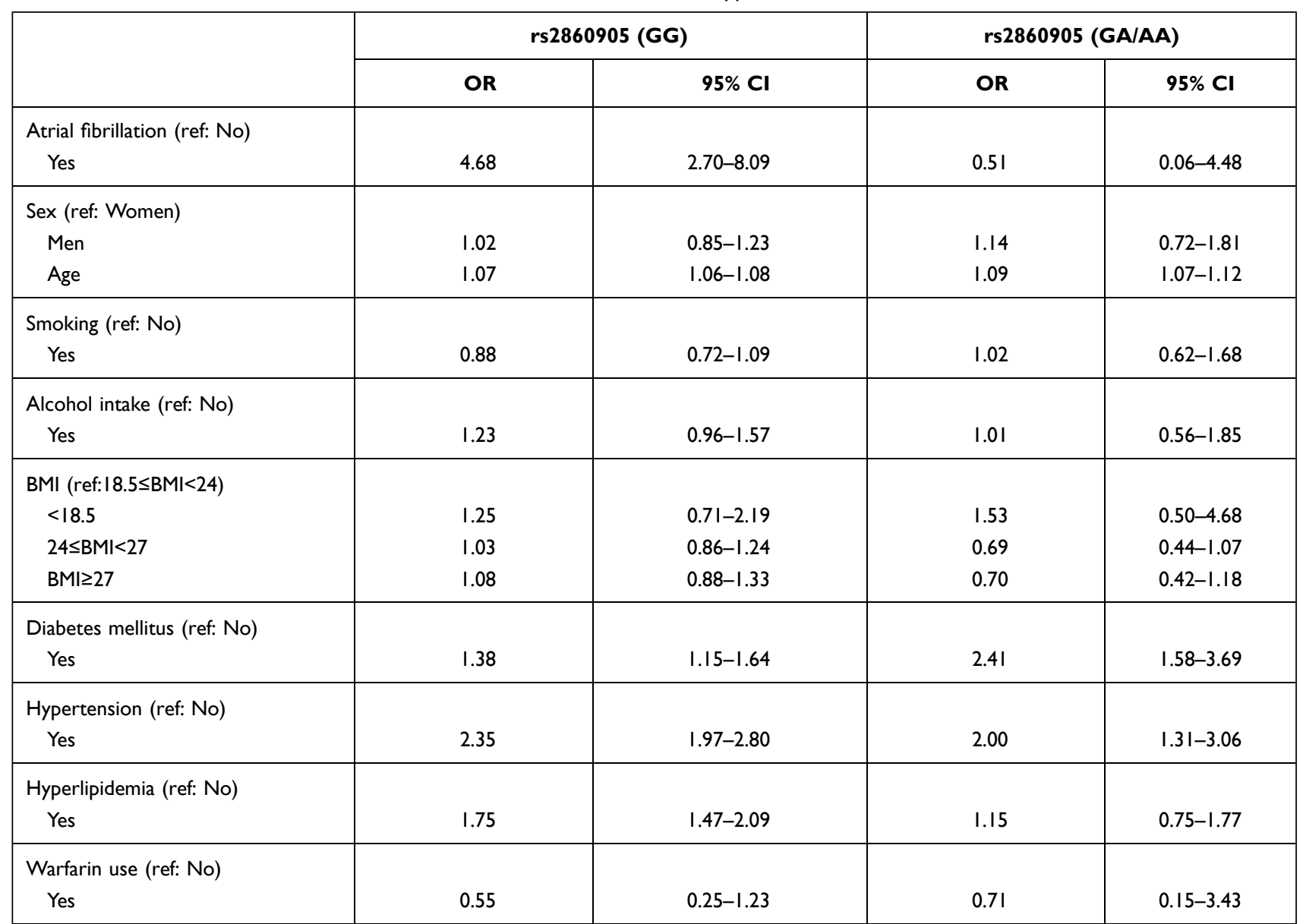

Note: Adjusted for physical activity and educational level.

significant. That is, the $95 \% \mathrm{CI}$ overlapped the null value (for instance, $\mathrm{OR}=1$ ).

\section{Discussion}

This study assessed the relationship between ischemic stroke and atrial fibrillation among those with rs2860905 polymorphism in Taiwan using linked data from TWB and the NHIRD. To our knowledge, such associations have not been reported in Taiwan. Initially, we observed that atrial fibrillation but not the rs2860905 variant was a significant risk factor for ischemic stroke. However, when we stratified by rs2860905 genotypes, we found that atrial fibrillation was a risk factor only among GG genotype individuals (OR, 4.68; 95\% C I: 2.7-8.09). On the contrary, the GA/AA genotype predicted a decreased but nonsignificant risk for ischemic stroke.

Strong associations have been observed between ischemic stroke and genome-wide measures of atrial fibrillation. ${ }^{17,18}$ The genetic variants previously analyzed were simply those that have shown associations with atrial fibrillation. ${ }^{18}$ In our study, we included a variant that has been previously linked to warfarin use. Of note, warfarin decreases the risk of ischemic stroke ${ }^{9,10}$. However, its dose is affected by genetic variants, including the rs 2860905 variant. $^{13}$

Considering that the rs2860905 variant has not been replicated in Taiwan and little is known about it in Asia, we thought it wise to determine whether it contributes to the association between ischemic stroke and AF. We believe that our findings expand knowledge on the genetic basis of ischemic stroke in Taiwan.

We observed that other well-established risk factors for ischemic stroke like diabetes, ${ }^{19}$ hypertension, ${ }^{20}$ and hyperlipidemia $^{21}$ remained strongly associated with ischemic stroke risk. We also observed that the OR associated with warfarin use was lower even though it was not significant. Moreover, we found that the risk of ischemic stroke did not differ significantly between men and women. 
Table 4 The Odds of Ischemic Stroke Among Participants with and without Atrial Fibrillation

\begin{tabular}{|c|c|c|c|c|}
\hline & \multicolumn{2}{|c|}{$\begin{array}{l}\text { No Atrial } \\
\text { Fibrillation }\end{array}$} & \multicolumn{2}{|c|}{$\begin{array}{c}\text { Atrial } \\
\text { Fibrillation }\end{array}$} \\
\hline & OR & $95 \% \mathrm{Cl}$ & OR & $95 \% \mathrm{Cl}$ \\
\hline rs2860905 (ref: GG) & & & & \\
\hline $\mathrm{GA} / \mathrm{AA}$ & 1.04 & $0.85-1.26$ & 0.08 & $0.01-0.82$ \\
\hline Sex (ref: Women) & & & & \\
\hline Men & 1.04 & $0.87-1.24$ & 0.94 & $0.23-3.89$ \\
\hline Age & 1.07 & $1.06-1.08$ & 1.02 & $0.93-1.12$ \\
\hline Smoking (ref: No) & & & & \\
\hline Yes & 0.91 & $0.75-1.10$ & 0.40 & $0.10-1.66$ \\
\hline Alcohol intake (ref: No) & & & & \\
\hline Yes & 1.22 & $0.97-1.54$ & 0.48 & $0.06-3.72$ \\
\hline BMI (ref: $18.5 \leq$ BMI<24) & & & & \\
\hline$<18.5$ & 1.30 & $0.79-2.14$ & - & - \\
\hline $24 \leq \mathrm{BMI}<27$ & 0.97 & $0.82-1.15$ & 1.49 & $0.39-5.69$ \\
\hline $\mathrm{BMI} \geq 27$ & 0.99 & $0.82-1.20$ & 3.75 & $0.83-16.95$ \\
\hline Diabetes mellitus (ref: No) & & & & \\
\hline Yes & 1.48 & $1.26-1.75$ & 2.21 & $0.63-7.76$ \\
\hline Hypertension (ref: No) & & & & \\
\hline Yes & 2.27 & $1.92-2.67$ & 4.79 & $1.23-18.70$ \\
\hline Hyperlipidemia (ref: No) & & & & \\
\hline Yes & 1.66 & $1.40-1.96$ & 1.79 & $0.57-5.60$ \\
\hline Warfarin use (ref: No) & & & & \\
\hline Yes & 0.76 & $0.32-1.78$ & 0.43 & $0.11-1.65$ \\
\hline
\end{tabular}

Note: Adjusted for physical activity and educational level.

Thus far, efforts have been made to determine the relationship between ischemic stroke and genetic variants even though results have been inconsistent. ${ }^{22}$ Previous studies in Taiwan replicated variants of other genes. ${ }^{23,24}$ Of note, they did not include atrial fibrillation in their model as we have done.

Having presented these findings, we also acknowledge a few limitations. First, patients with a severe type of ischemic stroke were not enrolled in the TWB. Therefore, we may have underestimated the number of people with ischemic stroke. Next, our results may be mediated by the pharmacodynamic effect of warfarin. However, we did not have information about the actual dose of warfarin, or the treatment details of participants. Despite these, our study highlights the genetic basis of ischemic stroke even though functional genomic studies are still needed to validate these findings.

\section{Conclusions}

Taken together, our findings indicate that the association between ischemic stroke and atrial fibrillation may be stronger among adults with the CYP2C9 rs2860905 GG genotype. Further studies would be required to see whether the results reported here apply to other populations.

\section{Funding}

This work was supported by grants (MOST 107-2627M-040-002, MOST 108-2621-M-040-001, MOST 1092121-M-040-002) from the Ministry of Science and Technology. The funders had no role in study design, data collection and analysis, decision to publish, or preparation of the manuscript.

\section{Disclosure}

The authors report no conflicts of interest in this work.

\section{References}

1. Lindsay MP, Norrving B, Sacco RL, et al. World Stroke Organization (WSO): Global Stroke Fact Sheet 2019. London, England: SAGE Publications Sage UK; 2019.

2. Malik R, Traylor M, Pulit SL, et al. Low-frequency and common genetic variation in ischemic stroke: the METASTROKE collaboration. Neurology. 2016;86(13):1217-1226. doi:10.1212/ WNL.0000000000002528

3. Chen CY, Huang YB, Tzu-Chi Lee C. Epidemiology and disease burden of ischemic stroke in Taiwan. Int J Neurosci. 2013;123 (10):724-731. doi:10.3109/00207454.2013.796552

4. Feigin VL, Nichols E, Alam T, et al. Global, regional, and national burden of neurological disorders, 1990-2016: a systematic analysis for the Global Burden of Disease Study 2016. Lancet Neurol. 2019;18(5):459-480. doi:10.1016/S1474-4422(18)30499-X

5. Lin LY, Lee $\mathrm{CH}, \mathrm{Yu} \mathrm{CC}$, et al. Risk factors and incidence of ischemic stroke in Taiwanese with nonvalvular atrial fibrillation-a nation wide database analysis. Atherosclerosis. 2011;217(1):292-295. doi:10.1016/j.atherosclerosis.2011.03.033

6. Hägg S, Thorn LM, Forsblom CM, et al. Different risk factor profiles for ischemic and hemorrhagic stroke in type 1 diabetes mellitus. Stroke. 2014;45(9):2558-2562. doi:10.1161/STROKEAHA. 114.005724

7. Healey JS, Connolly SJ, Gold MR, et al. Subclinical atrial fibrillation and the risk of stroke. $N$ Engl J Med. 2012;366(2):120-129. doi:10.1056/NEJMoa1105575

8. Kamel H, Okin PM, Elkind MS, Iadecola C. Atrial fibrillation and mechanisms of stroke: time for a new model. Stroke. 2016;47 (3):895-900. doi:10.1161/STROKEAHA.115.012004

9. Kaithoju S. Ischemic stroke: risk stratification, warfarin teatment and outcome measure. J Atr Fibrillation. 2015;8(4). doi:10.4022/ jafib. 1144

10. Deedwania PC. New oral anticoagulants in elderly patients with atrial fibrillation. Am J Med. 2013;126(4):289-296. doi:10.1016/j. amjmed.2012.10.012

11. Yang J, Chen Y, Li X, et al. Influence of CYP2C9 and VKORC1 genotypes on the risk of hemorrhagic complications in warfarin-treated patients: a systematic review and meta-analysis. Int $J \quad$ Cardiol. 2013;168(4):4234-4243. doi:10.1016/j. ijcard.2013.07.151 
12. Wadelius M, Chen LY, Eriksson N, et al. Association of warfarin dose with genes involved in its action and metabolism. Hum Genet. 2007;121(1):23-34. doi:10.1007/s00439-006-0260-8

13. Claudio-Campos K, Labastida A, Ramos A, et al. Warfarin anticoagulation therapy in Caribbean Hispanics of Puerto Rico: a candidate gene association study. Front Pharmacol. 2017;8:347. doi:10.3389/fphar.2017.00347

14. Liu YT, Nfor ON, Wang L, et al. Interaction between sex and LDLR rs688 polymorphism on hyperlipidemia among Taiwan Biobank adult participants. Biomolecules. 2020;10(2):244. doi:10.3390/ biom 10020244

15. Buniello A, MacArthur JA, Cerezo M, et al. The NHGRI-EBI GWAS Catalog of published genome-wide association studies, targeted arrays and summary statistics 2019. Nucleic Acids Res. 2019;47 (D1):D1005-D1012. doi:10.1093/nar/gky1120

16. Ahmed S, Mumtaz MN, Zulfiqar Z, et al. Genetic variations in drug-metabolizing enzyme CYP2C9 among major ethnic groups of Pakistani population. Gene. 2020;746:144659.

17. Lubitz SA, Parsons OE, Anderson CD, et al. Atrial fibrillation genetic risk and ischemic stroke mechanisms. Stroke. 2017;48(6):1451-1456. doi:10.1161/STROKEAHA.116.016198

18. Tada H, Shiffman D, Smith JG, et al. Twelve-single nucleotide polymorphism genetic risk score identifies individuals at increased risk for future atrial fibrillation and stroke. Stroke. 2014;45 (10):2856-2862. doi:10.1161/STROKEAHA.114.006072
19. Chen R, Ovbiagele B, Feng W. Diabetes and stroke: epidemiology, pathophysiology, pharmaceuticals and outcomes. Am J Med Sci. 2016;351(4):380-386. doi:10.1016/j.amjms.2016.01.011

20. Gorgui J, Gorshkov M, Khan N, Daskalopoulou SS. Hypertension as a risk factor for ischemic stroke in women. Can J Cardiol. 2014;30 (7):774-782. doi:10.1016/j.cjca.2014.01.007

21. Djelilovic-Vranic J, Tiric-Campara M, Subašić N, Alajbegovic A, Todorović L. Hyperlipidemia-risk factor for development of ischemic stroke: P2254. Eur J Neurol. 2010;17.

22. Lindgren A. Stroke genetics: a review and update. J Stroke. 2014;16 (3):114. doi:10.5853/jos.2014.16.3.114

23. Hsieh MS, Yu SC, Chung WT, et al. Phosphodiesterase 4d (PDE4D) gene variants and risk of ischemic stroke in the Taiwanese population. Lab Med. 2009;40(2):87-90. doi:10.1309/ LM4X5PCRN4AECXBB

24. Hsieh YC, Seshadri S, Chung WT, et al. Association between genetic variant on chromosome 12 p13 and stroke survival and recurrence: a one year prospective study in Taiwan. J Biomed Sci. 2012;19(1):1. doi:10.1186/1423-0127-19-1

\section{Publish your work in this journal}

Pharmacogenomics and Personalized Medicine is an international, peer-reviewed, open access journal characterizing the influence of genotype on pharmacology leading to the development of personalized treatment programs and individualized drug selection for improved safety, efficacy and sustainability. This journal is indexed on the American Chemical Society's Chemical Abstracts Service (CAS). The manuscript management system is completely online and includes a very quick and fair peer-review system, which is all easy to use. Visit http://www.dovepress.com/testimonials.php to read real quotes from published authors. 